\title{
PATHOGENIC SYNERGY BETWEEN ESCHERICHIA COLI AND BACTEROIDES FRAGILIS: STUDIES IN AN EXPERIMENTAL MOUSE MODEL
}

\author{
A. M. J. J. Verweij-van Vught, F. Namavar, M. Sparrius, W.A.C. Vel and \\ D. M. MACLAREN
}

\begin{abstract}
Research Group on Commensal Infections, Departments of Medical and Oral Microbiology, Schools of Medicine and Dentistry, Vrije Universiteit, P.O. Box 7161, 1007 MC Amsterdam, The Netherlands
\end{abstract}

\begin{abstract}
SUMmaRY. An animal model is described for quantitative evaluation of pathogenic synergy between Escherichia coli and Bacteroides fragilis in which adjuvants were not required for abscess formation. Two sets of strains of $E$. coli and $B$. fragilis isolated from human wound infections were tested. Pathogenic synergy was observed in only one of the two combinations and was dependent on properties of E. coli.
\end{abstract}

\section{INTRODUCTION}

The frequent presence of more than one bacterial species in infections such as intra-abdominal abscesses led to the concept of pathogenic synergy between bacteria (Meleney, 1931; Finegold, 1977; Kelly and Warren, 1978). Pathogenic synergy, especially between Escherichia coli and Bacteroides fragilis has been described by several authors (Onderdonk et al., 1976; Kelly, 1978; Mayrand and McBride, 1980; Carlson, 1982).

Various animal models have been developed to evaluate this synergy. The intra-abdominal sepsis model of Onderdonk et al. (1976) in rats clearly illustrated synergy between $E$. coli and $B$. fragilis in abscess formation and Kelly (1978) demonstrated this also in a guinea pig cutaneous wound model. Ingham et al. (1977) and Namavar et al. (1983) observed inhibition of phagocytosis of Proteus mirabilis by anaerobic bacteria, which may be one explanation of pathogenic synergy. This inhibition was not observed in vivo by Reznikov, Finlay-Jones and McDonald (1981), who studied the peritoneal clearance of $E$. coli in mice in the presence of $B$. fragilis, and Rodloff et al. (1981) were unable to demonstrate synergy between $E$. coli and $B$. fragilis in a mouse model of haematogenous infection.

The discrepancy in the findings of different authors may be due to differences in the models, the use of different bacterial strains or the presence or absence of adjuvants. The aim of the present investigation was to develop an animal model for evaluation of pathogenic synergy between $E$. coli and $B$. fragilis, if possible without the use of adjuvants. 


\section{MATERIALS AND METHODS}

Bacterial strains. The two pairs of E. coli and B. fragilis strains studied were isolated from wound infections in patients in the Academic Hospital of the Vrije Universiteit. E. coli strain EB1 and B. fragilis strain BE1 were isolated from the same abscess; no other bacterial species was cultured. E. coli strain BE4 and B. fragilis strain BE4, isolated from another patient, were accompanied by three other anaerobes: Acidaminococcus fermentans, Eubacterium lentum and $B$. distasonis. The strains of E. coli were identified by the API 20E (API system S.A., Montalieu Vercieu, France) and the anaerobic strains by BBL Minitek ${ }^{\circledR}$ Numerical Identification system (BBL Microbiology Systems, Becton Dickinson, USA).

Animals. Swiss Albino mice (TNO, Zeist, The Netherlands) weighing 20-25 g were used. The mice were raised under conventional conditions.

Inoculum preparation. Strains of E. coli were cultured aerobically in nutrient broth (Blood Agar Base No. 2, Oxoid) until in late logarithmic phase. Cells were harvested by centrifugation,

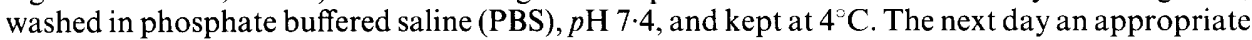
dilution was made in PBS, based on the viable count of the suspension. B. fragilis was grown in BM medium as described by Shah et al. (1976), supplemented with haemin $5 \mu \mathrm{g} / \mathrm{ml}$ and menadione $2 \mu \mathrm{g} / \mathrm{ml}$ at $37^{\circ} \mathrm{C}$ in an anaerobic jar in an atmosphere of $\mathrm{N}_{2} 80 \%, \mathrm{H}_{2} 10 \%$ and $\mathrm{CO}_{2}$ $10 \%$. Cultures were harvested after $20 \mathrm{~h}$ by centrifugation and resuspended in PBS. In some experiments whole cultures were used. A volume of $0.1 \mathrm{ml}$ of appropriate dilutions of the bacteria alone or in combination was injected subcutaneously in the back of mice at about $1 \mathrm{~cm}$ from the midline after shaving the skin (Simoons-Smit et al., 1984).

\section{Evaluation of abscess formation}

At different times animals were killed by chloroform inhalation, the skin was cleaned with alcohol $70 \% \mathrm{v} / \mathrm{v}$ and allowed to dry. Skin fragments, including the site of the lesion, were excised. For evaluation of the infection, three different methods were used (see below).

Minimal abscess-forming doses. Ten-fold dilutions of the strains of E. coli and two-fold dilutions of the strains of $B$. fragilis were injected alone and in various combinations with each other. Excised skin fragments of mice were examined macroscopically after 7 days for redness, swelling and pus formation. Only abscesses with pus formation were regarded as positive. The lowest dose producing abscesses in at least $50 \%$ of the mice was determined (minimal abscess-forming dose)

Growth index, a semiquantitative estimation of the number of bacteria in the skin lesion, was determined as described before (Simoons-Smit et al., 1984). Skin fragments were excised from dorsal to ventral and stretched. After macroscopic examination 5-mm parallel cuts at 4-mm interval were made starting from the periphery and working to the centre. Each lesion was sampled by rubbing a loop along both walls of each cut and plating on nutrient agar plates. After incubation at $37^{\circ} \mathrm{C}$ overnight the growth was graded as: 8 (confluent growth), 4 (semiconfluent growth), 2 ( $>20$ colonies), 1 ( $<20$ colonies) or 0 (no growth). For each strain, mean values of the growth indices in the separate cuts of the skin lesions were calculated.

Viable count of abscess content. At intervals after injection of bacteria, excised skin fragments including the whole abscesses were incised through the centre and homogenised in $5 \mathrm{ml}$ of PBS (Thomas Tissue Grinder, Philadelphia, USA). A viable count was made aerobically on nutrient agar for E. coli. For all experiments the results are based on at least eight infection sites.

\section{RESULTS}

The formation of abscesses in mice after subcutaneous injection of bacteria was strongly dependent on the dose used. Injection of $E$. coli $5 \times 10^{7} \mathrm{cfu}$ resulted in subcutaneous swelling with pus, which after a few days developed into a poorly delineated abscess. Spontaneous drainage through the skin occurred sometimes after 8 or 10 days with complete healing of the abscess. Only at high doses did some mice die 
TABLE

Minimal abscess-forming doses (cfu) of E. coli and B. fragilis alone or in combination

\begin{tabular}{|c|c|c|c|c|c|}
\hline \multirow{2}{*}{$\begin{array}{c}\text { Combination } \\
\text { of } \\
\text { strains }\end{array}$} & \multicolumn{5}{|c|}{ Minimal abscess-forming doses of } \\
\hline & E. coli & B. fragilis & E. coli & + & B. fragilis \\
\hline $\mathrm{EB} 1 / \mathrm{BE} 1 *$ & $5 \times 10^{6}$ & $>8 \times 10^{8}$ & $\left\{\begin{array}{l}5 \times 10^{5} \\
5 \times 10^{4}\end{array}\right.$ & $\begin{array}{l}+ \\
+\end{array}$ & $\begin{array}{r}2.5 \times 10^{7} \\
2 \times 10^{8}\end{array}$ \\
\hline $\mathrm{EB} 4 / \mathrm{BE} 4 *$ & $5 \times 10^{6}$ & $>8 \times 10^{8}$ & $5 \times 10^{6}$ & + & $1-8 \times 10^{8}$ \\
\hline $\mathrm{EB} 1 / \mathrm{BE} 1 \dagger$ & $5 \times 10^{7}$ & $>8 \times 10^{8}$ & $\left\{\begin{array}{l}5 \times 10^{5} \\
5 \times 10^{4}\end{array}\right.$ & $\begin{array}{l}+ \\
+\end{array}$ & $\begin{aligned}< & 1 \times 10^{8} \\
2 & \times 10^{8}\end{aligned}$ \\
\hline $\mathrm{EB} 4 / \mathrm{BE} 4 \dagger$ & $5 \times 10^{7}$ & $>8 \times 10^{8}$ & $5 \times 10^{7}$ & + & $1-8 \times 10^{8}$ \\
\hline
\end{tabular}

shortly after injection of the bacteria, probably due to the toxicity of the bacteria. With B. fragilis, abscesses developed only at doses of $>8 \times 10^{8} \mathrm{cfu}$ a few days after injection, and were more firm and sharply delineated, quite different from the abscesses caused by $E$. coli. Injection of a combination of these two species of bacteria resulted in abscesses resembling those produced by $E$. coli alone. The number of $E$. coli needed for abscess formation was much lower in the presence of $B$. fragilis, suggesting pathogenic synergy; this was evaluated in three different ways.

Determination of the minimal abscess-forming doses. For the two pairs of E. coli and $B$. fragilis, minimal abscess-forming doses were determined for the bacteria alone and in combination. The strains of $E$. coli were suspended in BM medium; undiluted cultures of $B$. fragilis in BM medium were used (table). The minimal abscess-forming dose of $E$. coli $\mathrm{EB} 1$ in the presence of $B$. fragilis $\mathrm{BE} 1$ was much lower than the dose of $E$. coli injected alone, whereas the number of $B$. fragilis $\mathrm{BE} 1$ used in combination with $E$. coli was not sufficient for abscess formation, when used alone. B. fragilis strain BE4 had no influence on the frequency of abscess formation by E. coli strain EB4. To study the effect of BM medium on the mimimal infective dose the same experiments were performed with all bacterial suspensions in PBS (table). Although BM medium had some effect on the infectivity of the bacterial strains, pathogenic synergy when present was also shown in the abscence of this medium.

Enumeration of the viable bacteria in the abscess. Determination of the number of bacteria in the abscess might possibly give some information about the degree of bacterial synergism. We used for this purpose the growth index, a semi-quantitative bacterial count as described by Maskell (1981) and Simoons-Smit et al. (1984). Mice were given injections of $0.1 \mathrm{ml}$ of $E$. coli $\left(1 \times 10^{6} \mathrm{cfu}\right)$ alone or of a mixture of $E$. coli $\left(1 \times 10^{6} \mathrm{cfu}\right)$ and $B$. fragilis $\left(5 \times 10^{7} \mathrm{cfu}\right)$. Only suspensions of bacteria in PBS were used. With this method pathogenic synergy between $E$. coli strain EB1 and B. fragilis strain BEl was established, whereas with the other pair again no synergy was found at the dose used (fig. 1). Pairing of the $E$. coli strains EB1 and EB4 with the $B$. fragilis strains $\mathrm{BE} 4$ and $\mathrm{BE} 1$ respectively revealed that synergy was dependent on properties of $E$. coli strain EB1. Both strains of B. fragilis enhanced the pathogenicity of E. coli strain EB1, but not that of $E$. coli strain EB4. The course of the infection was followed during 7 


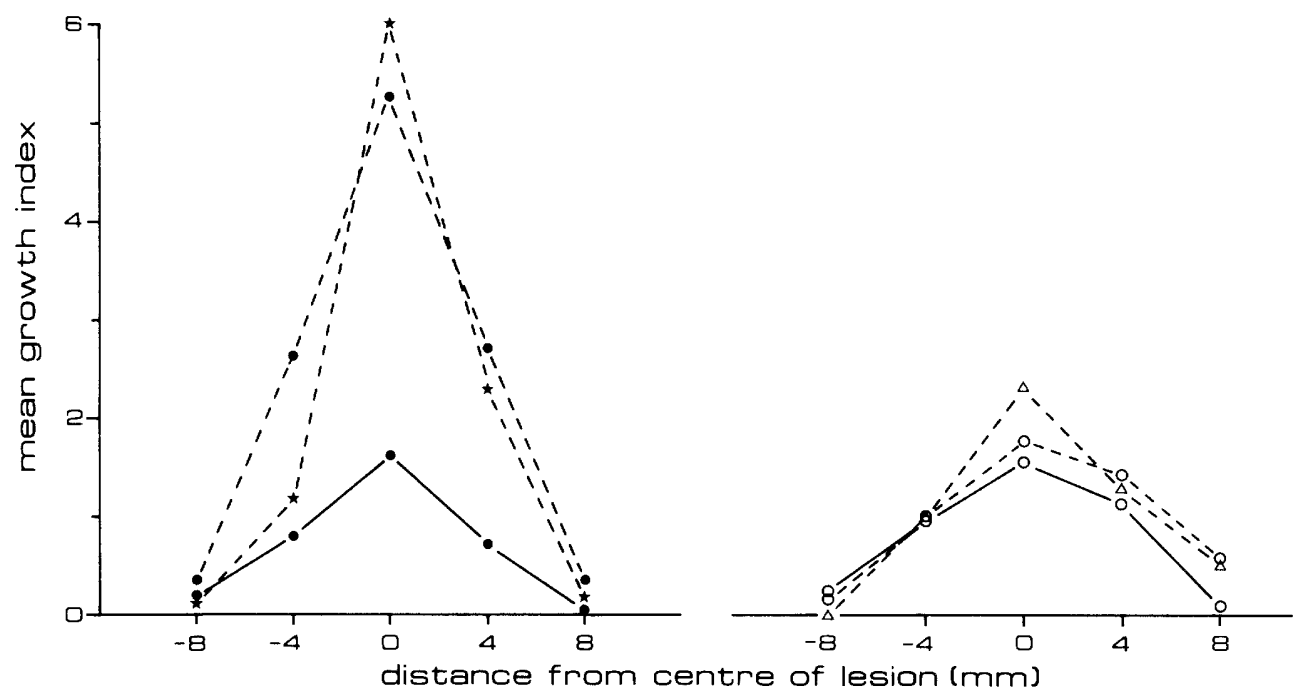

FIG. 1.-Concentration profiles of $E$. coli in skin lesions in mice after injection of $E$. coli alone ( -$)$ or in combination with B. fragilis (- - - ). Left: E. coli strain EB1 alone (-- ) or in the presence of $B$. fragilis strain BE1 (-...-) or strain BE4 $\left(^{*} \ldots-_{*}^{*}\right)$. Right: E. coli strain EB4 alone $(\mathrm{O}-\mathrm{O})$ or in the presence of $B$. fragilis strain BE4 $(0-\ldots)$ or strain BEl $(\triangle-\cdots \Delta)$. Each point represents the mean of results of at least eight lesions.

days (fig. 2). Whereas $E$. coli when injected alone, decreased rapidly after the first day, the growth index of $E$. coli injected together with $B$. fragilis showed no decline during the experiment.

Determination of the viable count of $E$. coli in the abscess (fig. 3) after injection of the same doses $\left(E\right.$. coli $1 \times 10^{6} \mathrm{cfu} \pm B$. fragilis $\left.5 \times 10^{7} \mathrm{cfu}\right)$ confirmed the semiquantitative counts but gave more information on the degree of synergy. Both strains of $E$. coli were cleared rapidly from the skin with a reduction factor of 10000 -fold after 7 days. In

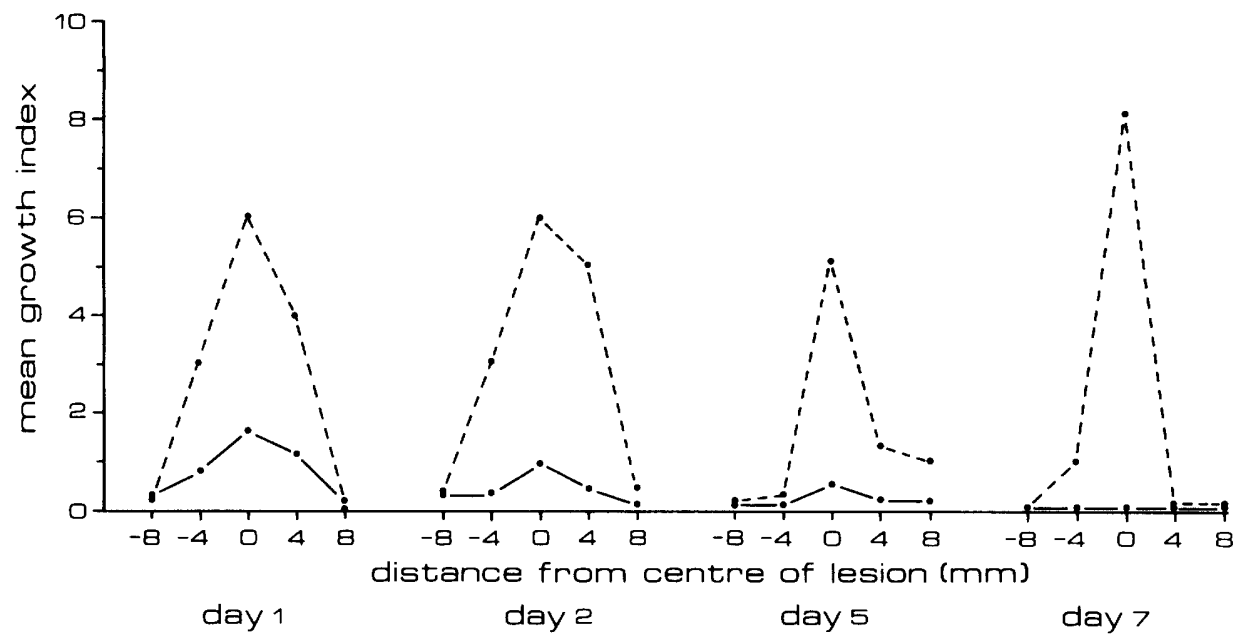

FIG. 2.-Progression of the infectious process of E. coli strain EB1 alone (-_ ) or in combination with $B$. fragilis strain BE1 (- - - - Each point represents the mean growth index value for E. coli of at least eight lesions. 


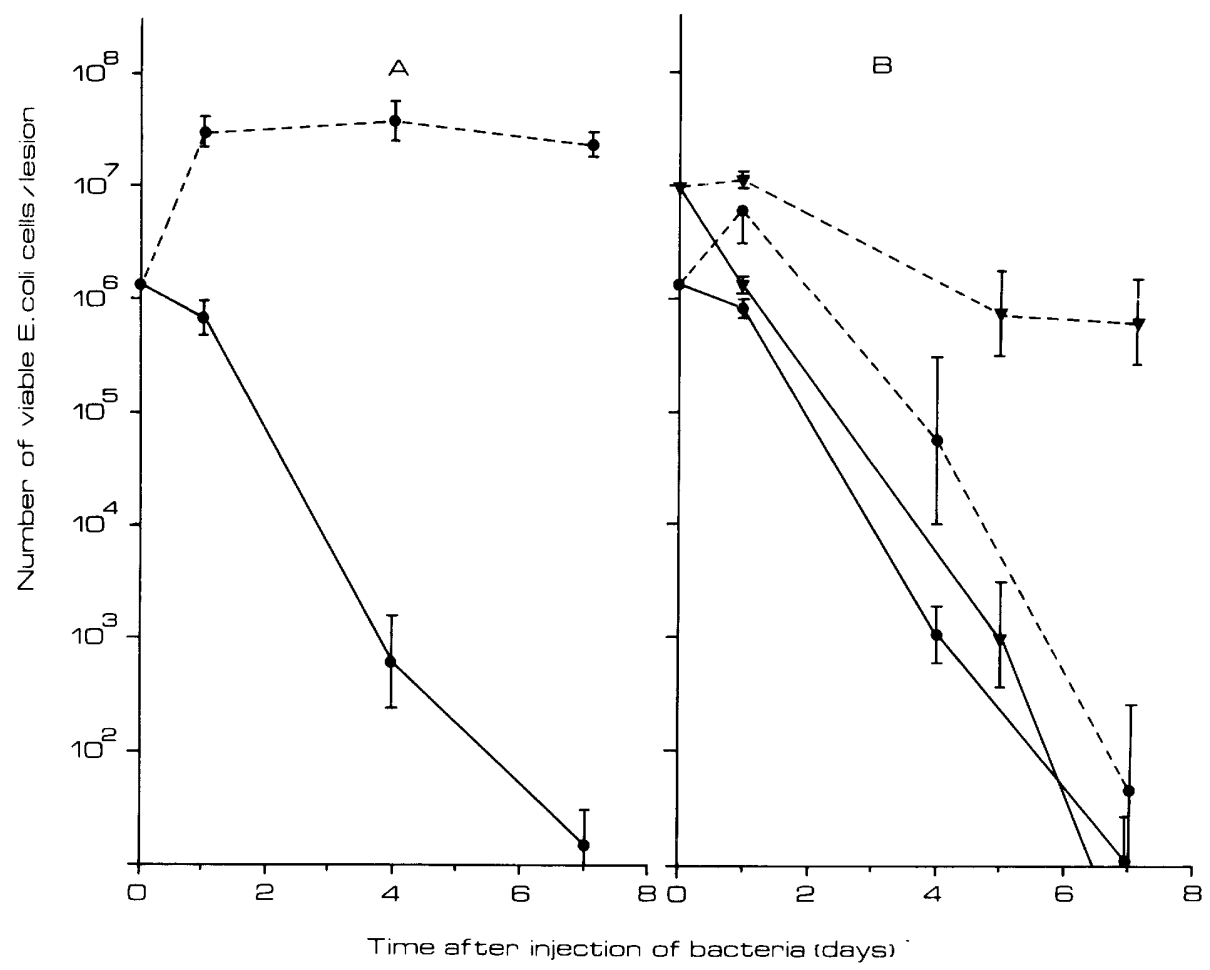

FIG. 3.-Numbers of viable $E$. coli in the wound homogenates after injection of $E$. coli strain 25 alone $\left(-\frac{}{-}\right)$ or in combination with $B$. fragilis (- . - .). The results with strains EB1 + BE1 and strains EB4 + BE4 are given in figs $\mathrm{A}$ and $\mathrm{B}$ respectively. The doses of $E$. coli were $1 \times 10^{6} \mathrm{cfu}(\bullet)$ or $1 \times 10^{7} \mathrm{cfu}(\boldsymbol{\nabla})$; the doses of $B$. fragilis were always $5 \times 10^{7} \mathrm{cfu}$. Each point represents the mean of results of at least eight lesions. SEM are indicated by bars.

the presence of $B$. fragilis strain BE1 counts of $E$. coli strain EB1 were enhanced and stayed high for at least 7 days (fig. 3A). The differences between $E$. colistrain EB1 alone and in combination with $B$. fragilis strain BE1 were significant (Student's $t$ test, $\mathrm{p}<0.001$ ). The presence of $B$. fragilis strain BE4 only had a marginal effect on the clearance of $E$. coli strain EB4. The differences were only significant (Student's $t$ test) at $\mathrm{t}=1 \mathrm{~h}(\mathrm{p}<0.02)$ and $\mathrm{t}=4 \mathrm{~h}(\mathrm{p}<0.05)$. Injection of a higher dose of $E$. coli strain EB4 $\left(1 \times 10^{7} \mathrm{cfu}\right)$ again resulted in a rapid clearance of $E$. coli from the skin of mice. However, a more pronounced effect of $B$. fragilis strain BE4 on the clearance was observed at this dose (fig. 3B). Abscesses which resulted from this combination usually healed within the 7 days of the experiment.

\section{DisCUSSION}

The aim of the present study was the development of a simple, reliable, economical animal model to evaluate pathogenic synergy between $E$. coli and Bacteroides spp., not dependent on the presence of adjuvants. A cutaneous animal model has been used for virulence studies by several authors (Joiner et al., 1980; Brook and Walker, 1983). High doses of $B$. fragilis were needed for abscess formation in the skin of mice in our 
experiments. This is in agreement with the observations of Brook and Walker (1983), who used a virtually identical model. Lower infective doses for B. fragilis have been reported, but always in the presence of adjuvants such as blood (Onderdonk et al., 1976), sutures (Kelly, 1978), sterile caecal contents and barium sulphate (Onderdonk et al., 1976) and croton oil and agar (Berti et al., 1982). The animal model described here clearly points to pathogenic synergy between $E$. coli strain EB1 and B. fragilis strains BE1 and BE4 but not between $E$. coli strain EB4 and B. fragilis strain BE4. The enhancement of growth of only one strain of $E$. coli indicates that this phenomenon depends on properties of these strains. The presence of growth medium markedly influenced the minimal infective doses but we do not agree with Rodloff (1983) that synergy is dependent solely on the presence of growth medium, as the effect of $B$. fragilis remained in the absence of the medium. Because the medium was not a prerequisite for abscess formation its further use was avoided.

The kinetic experiments showed a rapid clearance of both strains of $E$. coli when injected alone. At a dose of $1 \times 10^{6} \mathrm{cfu}$ of $E$. coli a substantial influence on the clearance by $B$. fragilis was only observed for $E$. coli strain EB1. At a higher dose this effect on the clearance was also observed for $E$. coli strain EB4, but did not necessarily result in long lasting abscesses. The differences between the strains of $E$. coli observed here may be due to differences in virulence factors; this is the subject of further research. Such differences may also partly explain discrepancies between the present results and those of other workers.

The mechanism of pathogenic synergy remains unclear. Some authors have reported inhibition of phagocytosis of facultative aerobes in the presence of anaerobes (Ingham et al., 1977; Namavar et al., 1983). Other mechanisms such as growth stimulation of $B$. fragilis by $E$. coli as suggested by Hagen et al. (1982) may also be involved. The fate of the bacteria during the first $24 \mathrm{~h}$ of the experiments has been shown to be crucial for the outcome of infection (Miles et al. 1957; Gorrill, 1965). Our model shows that in the presence of $B$. fragilis the clearance of $E$. coli from the skin of mice was reduced and multiplication occurred in vivo. The initial multiplication might be enough to establish the infection, but it is not yet known whether both organisms are needed after this initial period. Both organisms were invariably present when pus was cultured, even after 3 weeks. Further experiments will be needed to determine the exact roles of $E$. coli and $B$. fragilis during initiation and progression of the infection. The mouse model described here provides us with a simple and reproducible model for evaluation of pathogenic synergy, which is independent of adjuvants and discriminates between strains.

The skilful technical assistance of $\mathrm{Mr} \mathrm{W}$. Schouten was greatly appreciated.

\section{REFERENCES}

Berti M, Rossi E, Candiani G, Arioli V 1982 A new model of experimental Bacteroides fragilis infection in mice and rats. Chemotherapy 28:213-217.

Brook I, Walker R I 1983 Infectivity of organisms recovered from polymicrobial abscesses. Infection and Immunity 42:986-989.

Carlson E 1982 Synergistic effect of Candida albicans and Staphylococcus aureus on mouse mortality. Infection and Immunity 38:921-924.

Finegold S M 1977 Anaerobic bacteria in human disease. Academic Press, New York. 
Gorrill R H 1965 The fate of Pseudomonas aeruginosa, Proteus mirabilis, and Escherichia coli in the mouse kidney. Journal of Pathology and Bacteriology 89:81-88.

Hagen J C, Wood W S, Hashimoto T 1982 In vitro stimulation of Bacteroides fragilis growth by Escherichia coli. European Journal of Clinical Microbiology 1:338-343.

Ingham H R, Sisson P R, Tharagonnet D, Selkon J B, Codd A A 1977 Inhibition of phagocytosis in vitro by obligate anaerobes. Lancet 2:1252-1254.

Joiner K A, Onderdonk A B, Gelfand J A, Bartlett J G, Gorbach S L 1980 A quantitative model for subcutaneous abscess formation in mice. British Journal of Experimental Pathology 61:97-107.

Kelly M J 1978 The quantitative and histological demonstration of pathogenic synergy between Escherichia coli and Bacteroides fragilis in guinea pig wounds. Journal of Medical Microbiology 11:513-523.

Kelly M J, Warren R E 1978 The value of an operative wound swab sent in transport medium in the prediction of later clinical wound infection: a controlled clinical and bacteriological evaluation. British Journal of Surgery 65:81-88.

Maskell J P 1981 The pathogenicity of Bacteroides fragilis and related species estimated by intracutaneous injection in the guinea pig. Journal of Medical Microbiology 14:131-140.

Mayrand D, McBride B C 1980 Ecological relationships of bacteria involved in a simple, mixed anaerobic infection. Infection and Immunity 27:44-50.

Meleney F L 1931 Bacterial synergism in disease processes, with confirmation of synergistic bacterial etiology of certain types of progressive gangrene of the abdominal wall. Annals of Surgery 94:961-981.

Miles A A, Miles E M, Burke J 1957 The value and duration of defence reactions of the skin to the primary lodgement of bacteria. British Journal of Experimental Pathology 38:79-96.

Namavar F, Verweij A M J J, Bal M, Van Steenbergen T J M, De Graaff J, MacLaren D M 1983 Effect of anaerobic bacteria on killing of Proteus mirabilis by human polymorphonuclear leukocytes. Infection and Immunity 40:930-935.

Onderdonk A B, Bartlett J G, Louie T, Sullivan-Seigler N, Gorbach S L 1976 Microbial synergy in experienced intra-abdominal abscess. Infection and Immunity 13:22-26.

Reznikov M, Finlay-Jones J J, McDonald P J 1981 Effect of Bacteroides fragilis on the peritoneal clearance of Escherichia coli in mice. Infection and Immunity 32:398-399.

Rodloff A C, Rodloff S, Fischer B, Hahn H 1983 Intravenous injection of mice with Bacteroides fragilis and Escherichia coli: Role of thioglycollate medium in the infectious process. Zentralblatt für Bakteriologie, Parasitenkunde, InfektionsKrankheiten und Hygiene I Abt. Orig. A 254:405-412.

Shah H N, Williams R A D, Bowden G H, Hardie J M 1976 Comparison of the biochemical properties of Bacteroides melaninogenicus from human dental plaque and other sites. Journal of Applied Bacteriology 41:473-492.

Simoons-Smit A M, Verweij-van Vught A M J J, Kanis I Y R, MacLaren D M 1984 Virulence of Klebsiella strains in experimentally induced skin lesions in the mouse. Journal of Medical Microbiology 17:67-77. 